\title{
Plate Lines Reduce Lifetime of Wake Vortices During Final Approach to Vienna Airport
}

\author{
Frank Holzäpfel*, Anton Stephan, Grigory Rotshteyn \\ Institut für Physik der Atmosphäre, Deutsches Zentrum für Luft- und Raumfahrt, \\ 82234 Oberpfaffenhofen, Germany
}

\begin{abstract}
To mitigate the risk of wake vortex encounters during final approach, so-called plate lines have been developed. Wake vortices generated by landing aircraft induce secondary vortices at the plates' surfaces that approach the primary vortices and trigger premature wake vortex decay. Each plate line consists of several upright plates that are installed underneath the approach glide path. While the plate line extends perpendicular to the flight direction, its individual plates are oriented in parallel to the runway centerline. In order to obtain the approval of the authorities for the installation of the plate lines at runway 16 of Vienna International Airport, the plate design had to comply with airport requirements like obstacle clearance, stability, and frangibility. During a six-month campaign wake vortex behavior with and without plates was measured simultaneously by three lidars completed by a comprehensive suite of meteorological instrumentation. A preliminary analysis of 430 measured wake vortex evolutions indicates that the plate lines reduce the lifetime of longlived vortices in a safety corridor along the final approach on average by more than $30 \%$. More comprehensive analyses are underway and will be presented at the AVIATION Forum 2020 in Reno.
\end{abstract}

\section{Introduction}

A $\mathrm{S}$ an unavoidable consequence of lift, every flying vehicle generates counter-rotating regions of turbulence known as wake vortices ${ }^{1}$. Wake vortices represent a potential threat to following air traffic. Aircraft must therefore keep to a predetermined minimum separation distance. These aircraft separations limit the capacity of congested airports in a rapidly growing aeronautical environment. The most likely economic scenario for the future European airport demand indicates that there will be around 1.5 million unaccommodated flights in 2040, constituting approximately $8 \%$ of the expected demand ${ }^{2}$. Such a lack of capacity could mean 160 million passengers would not be able to travel with a potential economic loss of around $€ 88$ billion to the European economy.

In the recent years wake turbulence separations have been readjusted for new aircraft types, new arrival procedures, and modified aircraft weight categories. Whereas an unprecedented test program including many different phases of flight was accomplished for the determination of appropriate separation standards of the A380, most other new developments focused mainly on wake vortex evolution in ground proximity.

The B747-8 lidar measurement program conducted wake measurements at one wing span above ground, because this altitude was considered the most hazardous scenario ${ }^{7}$. Also the lidar measurements employed for the development of the time-based separations procedures at London Heathrow airport focused on the same flight altitude. The time-based separations concept helps to maintain landing rates in strong headwinds by adjusting aircraft separations according to the current headwind strength ${ }^{8}$.

The rationale for this substantial constraint is that most encounters occur at flight altitudes below $300 \mathrm{ft}$ (see Refs. 3, 4). In ground proximity vortex descent is restricted and the vortices tend to rebound due to the interaction with the ground surface. Weak crosswinds may compensate the self-induced lateral propagation of the upwind vortex, such that it may hover over the runway directly in the flight path of the following aircraft ${ }^{5}$. As a consequence aircraft experience wake vortex encounters time after time, even under adherence to separation standards ${ }^{6}$. During final approach, pilots usually respond to encounters by initiating go-arounds, since their options to counteract the imposed rolling moment and re-stabilize the approach are restricted at low heights above ground.

The same flight height restriction applies to the aircraft wake turbulence re-categorization initiative (RECAT) of ICAO. RECAT Phase 1 classifies aircraft types into six categories considering besides the weight the approach speed, wing characteristics and in parts also the rolling moment exerted on following aircraft. RECAT-1 has been implemented in November 2012 at Memphis airport ${ }^{9}$, followed by numerous other US airports. The new European

\footnotetext{
* Senior Scientist, frank.holzaepfel@dlr.de, Associate Fellow AIAA
} 
separation standard for aircraft wake turbulence called RECAT-EU has been first introduced for arrivals and departures at Charles de Gaulle airport Paris in March 2016 followed by the airports London-Heathrow, Leipzig/Halle, and Toulouse ${ }^{10}$. The long-term goal of the RECAT initiative is to introduce dynamic pair-wise separations that consider the aircraft type pairing (pair-wise) and the environmental conditions (dynamic). In SESAR2020 the envisaged developments for static pair wise separations and weather dependent reduced wake turbulence separations for arrival and departure also focus on wake evolution in the same height range.

To mitigate the risk of wake encounters during final approach and, in a next step, to improve runway capacity, so-called plate lines have been developed ${ }^{11}$. Each plate line consists of several upright plates that are installed beyond the ends of runways underneath the approach glide path perpendicular to the runway centerline. Secondary vortices detach from the individual plates' surfaces, actively approach the primary vortices, and interact with those such that the wake vortex lifetime is reduced. Previous investigations of the plate line principle comprise towing tank experiments ${ }^{13}$, large eddy simulations ${ }^{12,13,14}$, and flight experiments with DLR's research aircraft HALO ${ }^{11}$. Here we report the first installation of plate lines at an international airport and simultaneous measurements of the wake vortices with three lidars completed by a comprehensive suite of meteorological instrumentation.

\section{Previous Investigations of Plate Line Effects}

Before the current project, the plate line principle has been thoroughly investigated. First, fundamental research was conducted employing a towing tank through which a simplified aircraft model was towed and the flow was visualized with dy $\mathrm{e}^{13}$. Initially, a rod-shaped massive obstacle was placed at the ground to trigger premature vortex decay. Quantitative measurements were conducted with particle image velocimetry indicating substantially accelerated vortex decay rates above and close to the obstacle at the ground ${ }^{13}$.

Large eddy simulations (LES) were used to better understand the underlying vortex dynamics ${ }^{13}$. When the wake vortices get close to the obstacle, strong secondary vortices are shed from the obstacle's surface that actively approach the wake vortices (see Figure 1, left). Then the secondary vortices are wrapped around the wake vortices by the primary wake vortex flow (Figure 1, center). Finally, the secondary vortices propagate actively along either side of the wake vortices and accelerate their decay (Figure 1, right).

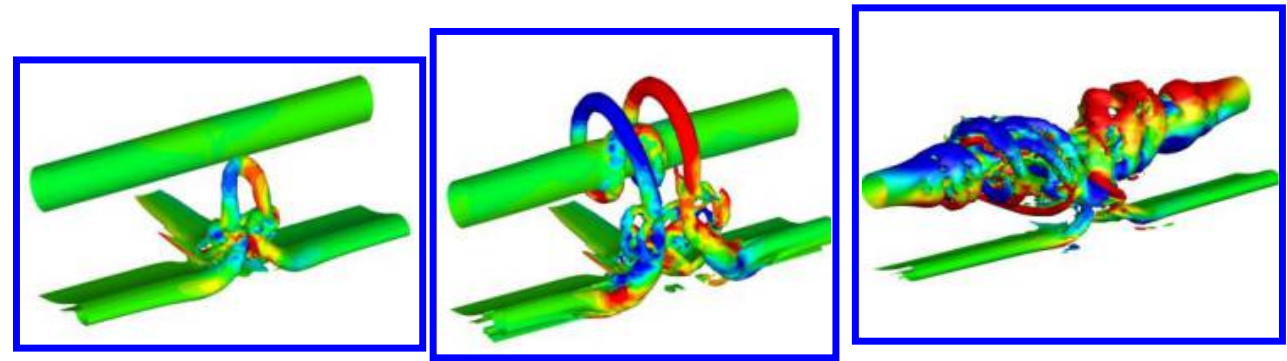

Figure $1 \Omega$-shaped secondary vortex approaches wake vortex and wraps around it leading to premature wake vortex decay.

In order to enable an installation at an airport, the massive obstacle was replaced by a series of plates, where the individual plates are aligned with the flight direction. LES showed that the effects of a plate line are even superior to those of a massive obstacle which can be attributed to the increased surface roughness of the plates compared to the smooth obstacle ${ }^{12}$. LES were used to optimize the plate shape ${ }^{14,15,16}$ and to investigate the impact of crosswind and headwind $^{12}$. As a result, a plate line with optimized plate dimensions of $4.5 \mathrm{~m}$ height and $9 \mathrm{~m}$ length, consisting of 8 plates and a plate separation of $20 \mathrm{~m}$ was designed. A respective patent has been filed under number DE 102011 010147 followed by international patents in the countries Austria, France, Great Britain, Japan, Singapore, and Switzerland. The patent in the USA was refused.

Finally, flight experiments were conducted with the DLR research aircraft HALO (Gulfstream G550) at special airport Oberpfaffenhofen ${ }^{11}$. HALO was flying traffic patterns in high-lift configuration at a constant height of about one initial vortex separation $b_{0}=22 \mathrm{~m}$ over a single plate line. The plate line consisted of six wooden plates that were erected laterally displaced from the runway. LiDAR measurement results indicated that the lifetime of the longest-lived and thus potentially most hazardous wake vortex could be reduced by one third ${ }^{11}$. 


\section{Plate Design and Approval of Authorities}

Several potential plate designs have been developed prior to the installation at Vienna airport. For example, a permanent design consisting of aluminum lattice masts certified for airports covered by truck tarpaulin and fixed to the ground by concrete foundations. Another low-cost, robust, and safe alternative were thuja hedges where the wind force would be distributed on many flexible stems. However, Vienna airport opted for the development of a temporal plate line design that can be removed easily after the live trial. A permanent design should only be considered after the benefits of the plate lines have been demonstrated.

The developed plate line design for temporary installation consists of four wooden frames covered by truck tarpaulin with a height of $4.5 \mathrm{~m}$ and a length of $2.25 \mathrm{~m}$, respectively (see Figure 2). A complete plate consisting of four elements has the dimensions of $4.5 \mathrm{~m}$ height and $9 \mathrm{~m}$ length. The plates are manufactured with hinges such that they can be folded up and down and secured at the ground when they are not used. The plates and the synthetic ropes are fixed to the ground with ground anchors.
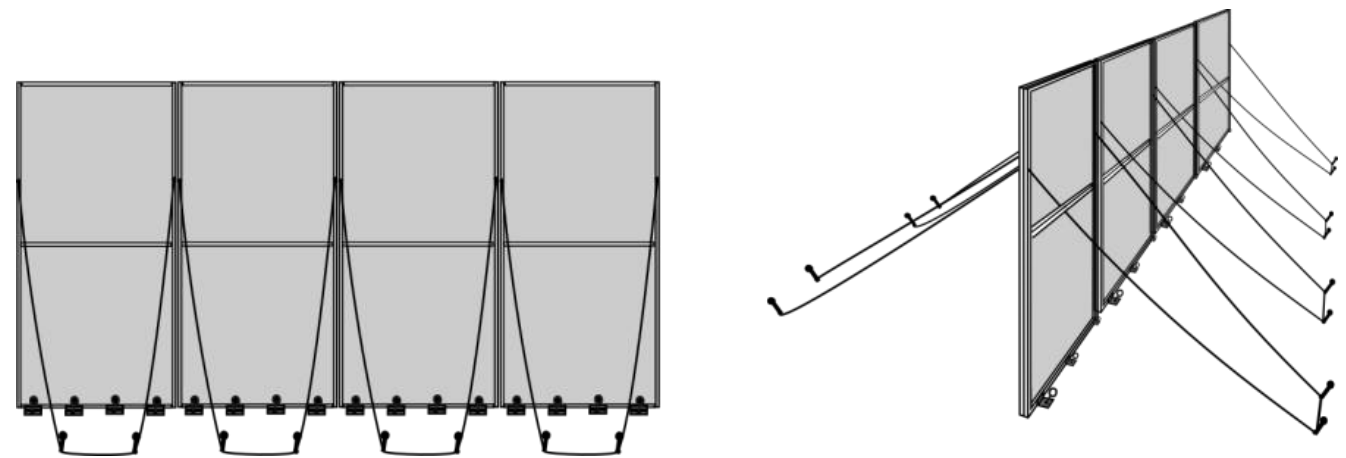

Figure 2 Plate line design for temporary installation.

The plates were designed for a maximum wind speed of $20 \mathrm{~m} / \mathrm{s}$ with a safety factor of $\mathrm{S}=3$. A stability test with a plate prototype during cyclone Friederike showed that the plate may resist winds of $15 \mathrm{~m} / \mathrm{s}(54 \mathrm{~km} / \mathrm{h}$, Bft 7) measured at $2 \mathrm{~m}$ above ground. An independent expert assessment confirmed the stability analysis regarding wind forces, the stability analysis of the ground anchors, and conducted a geotechnical assessment of the soil at runway 16 of Vienna airport. Finally, an assessment of the secured plates for winds of $200 \mathrm{~km} / \mathrm{h}$ was conducted in a wind tunnel to make sure that the secured plates would also resist heavy storms.

The University of Braunschweig proved the electromagnetic compatibility with the ILS localizer conducting measurements at scale 1:144. They found that even disturbances by steel plates are well within ICAO CAT III tolerances ${ }^{17}$. Nevertheless, it was decided to install the first plate line behind the localizer in order to avoid any impairment of the ILS signal which appeared to be already close to the tolerances due to other disturbances. 


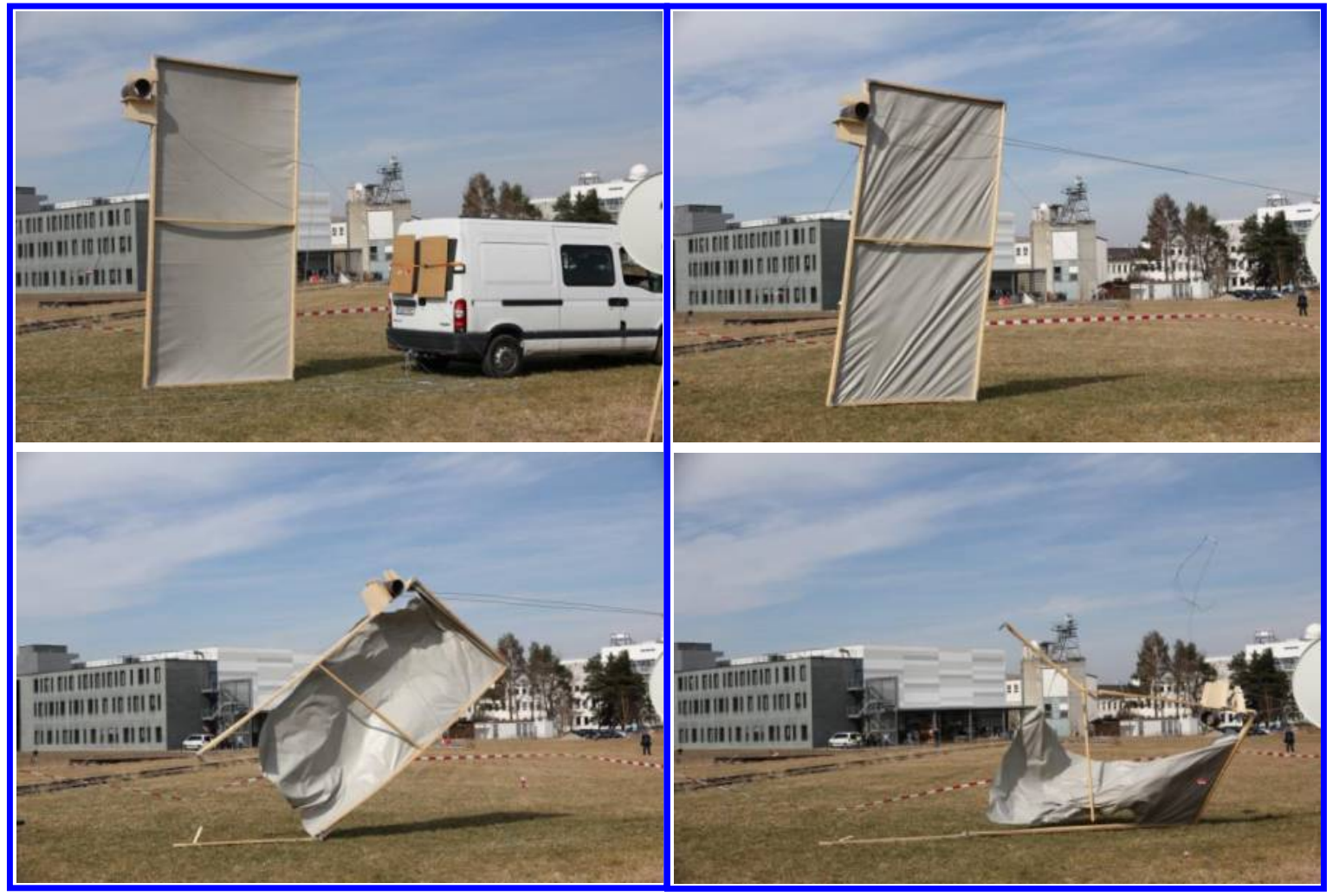

Figure 3 Frangibility test with prototype plate.

In order to comply with the frangibility requirements the plates feature predetermined breaking points in terms of dimensions of screws, metal brackets and anisotropic cross-sections of the wooden frames. Frangibility was demonstrated with a plate prototype according to the Autodrome Design Manual, Part 6 Frangibility of ICAO (see Figure 3). For this purpose a steel tube with outer diameter of $250 \mathrm{~mm}$, mimicking the leading edge of a wing, was mounted in $4 \mathrm{~m}$ height at the plate prototype. The steel tube was connected by a rope with a van that accelerated to about $35 \mathrm{~km} / \mathrm{h}$ before the rope got strained. A weak link with a breaking force of $10 \mathrm{kN}$ connected with the rope made sure that the prescribed maximum force of $45 \mathrm{kN}$ was not exceeded.

Substantial documentation of the plate design and placement, of the involved instrumentation and the procedures during the measurement campaign was produced. Based on this a safety assessment was conducted by the EASA Safety- \& Compliance Management of Vienna Int. Airport. Finally, the installation of the plates and the instrumentation was approved by the authorities (Bundesministerium für Verkehr, Innovation und Technologie, BMVIT). An Aeronautical Information Circular was established to inform the pilots without receiving any feedback. The measurement campaign started on 6 May 2019.

\section{Positioning of Plate Lines and Instrumentation}

Figure 4 shows the positioning of the plate lines (red dashes) and the instrumentation installed for the measurement campaign. The first plate line, consisting of 8 plates separated by $20 \mathrm{~m}$, is situated at a distance of about $400 \mathrm{~m}$ to the threshold of runway 16 . The two innermost plates are rotated by $13^{\circ}$ to avoid that the visibility of the approach lighting could be obscured. The second plate line consisting of 9 plates is placed at a distance of $320 \mathrm{~m}$ to plate line 1 . Nine plates were chosen to avoid placing one of the plates on the road way. 


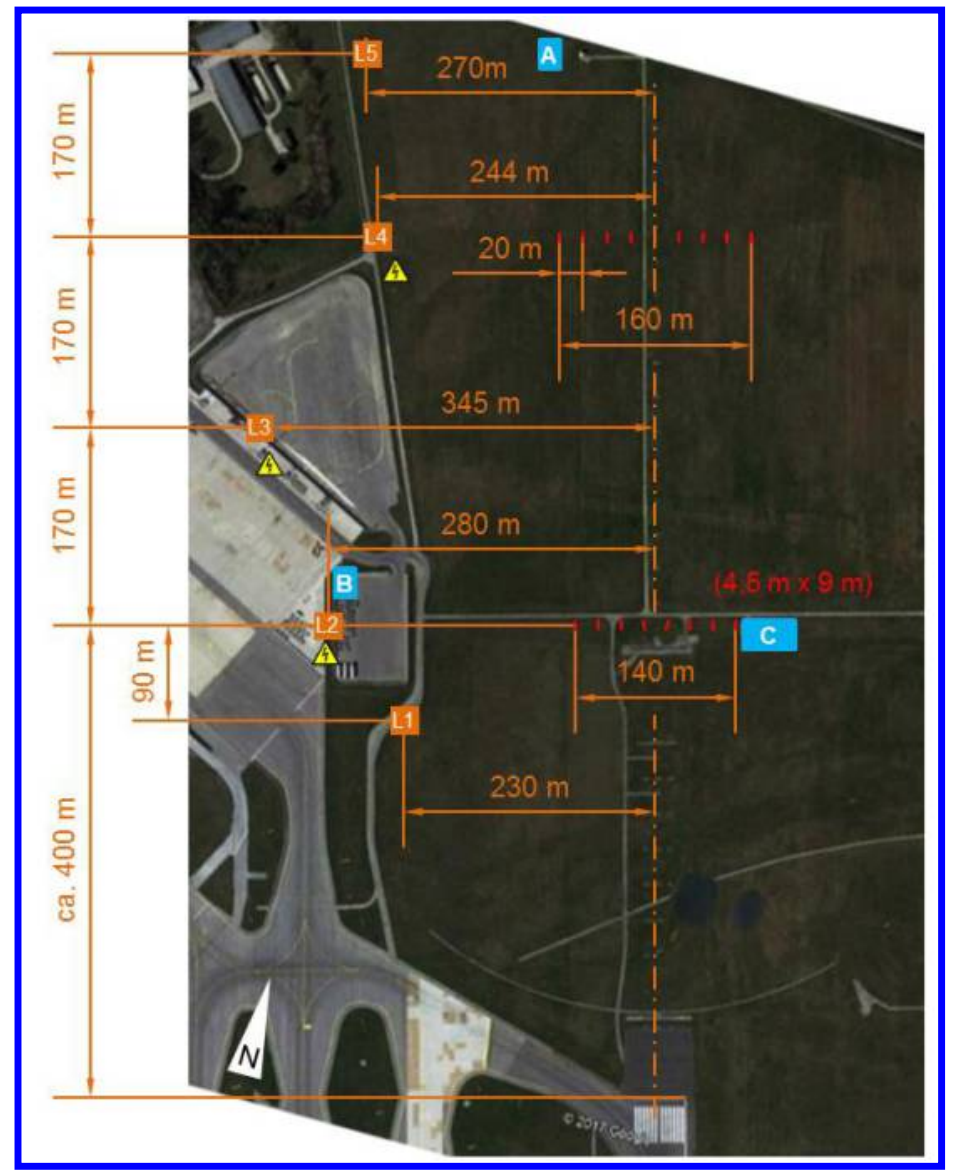

Figure 4 Positioning of plate lines and instrumentation (@) Google 2017).

Figure 4 shows the five measurement positions L1 - L5 of the lidars of type Leosphere Windcube 200S. The lidars were scanning in vertical planes perpendicular to the flight direction. Average flight altitudes above ground at the lidar planes L1 - L5 were determined from Mode-S data to $40.8 \mathrm{~m}, 45.8 \mathrm{~m}, 54.3 \mathrm{~m}, 64.8 \mathrm{~m}$, and $74.5 \mathrm{~m}$, respectively, with a standard deviation of $4.9 \mathrm{~m}$.

Lidar measurement planes L2 and L4 characterize wake vortex decay directly above a plate line for two different flight altitudes. Measurement plane L1 captures the interaction of the disturbances stemming, on the one hand, from touchdown (so-called end effects ${ }^{11,18}$ ) and, on the other, hand from the plates. Plane L3 measures the interaction of the disturbances spreading from the two plate lines, whereas L5 investigates the propagation of plate line disturbances against flight direction. Because only three lidars were available for the five measurement planes, three combinations of measurement planes were operated subsequently: (L1, L2, L3), (L2, L3, L4) und (L3, L4, L5). Measurements were conducted alternatingly with erected plates on one day and without plates on other days.

For a comprehensive wake vortex decay assessment, weather conditions have to be taken into account, which have a major impact on the lifetime of the vortices. Therefore, the following additional meteorological sensors were installed for this campaign. At position A the RPG Scintillometer Tx was placed. Position B hosted the RPG Doppler Cloud Radar RF Band. At the shelter in position C the RPG Scintillometer Rx, the RPG HATPRO Microwave Radiometer, the Axis M3027-PVE Fisheye Camera and the FLIR Infrared Camera were installed. Further, on the roof top of parking garage 4 the Leosphere Windcube 400S-AT Windlidar and the Leonardo Rainscanner 3D Weather Radar were placed (not shown).

The plates were manufactured in green color such that they could not be easily discriminated from the surrounding grass land. A pilot reported that the erected plates were barely visible from the cockpit of an aircraft on approach and he was arguing whether the plates were already removed when he tried to spot them. Figure 5 shows impressions of the installation of plate line 2, the visitors' day, and overflights of plate line 1 located at the localizer (in clockwise order). 


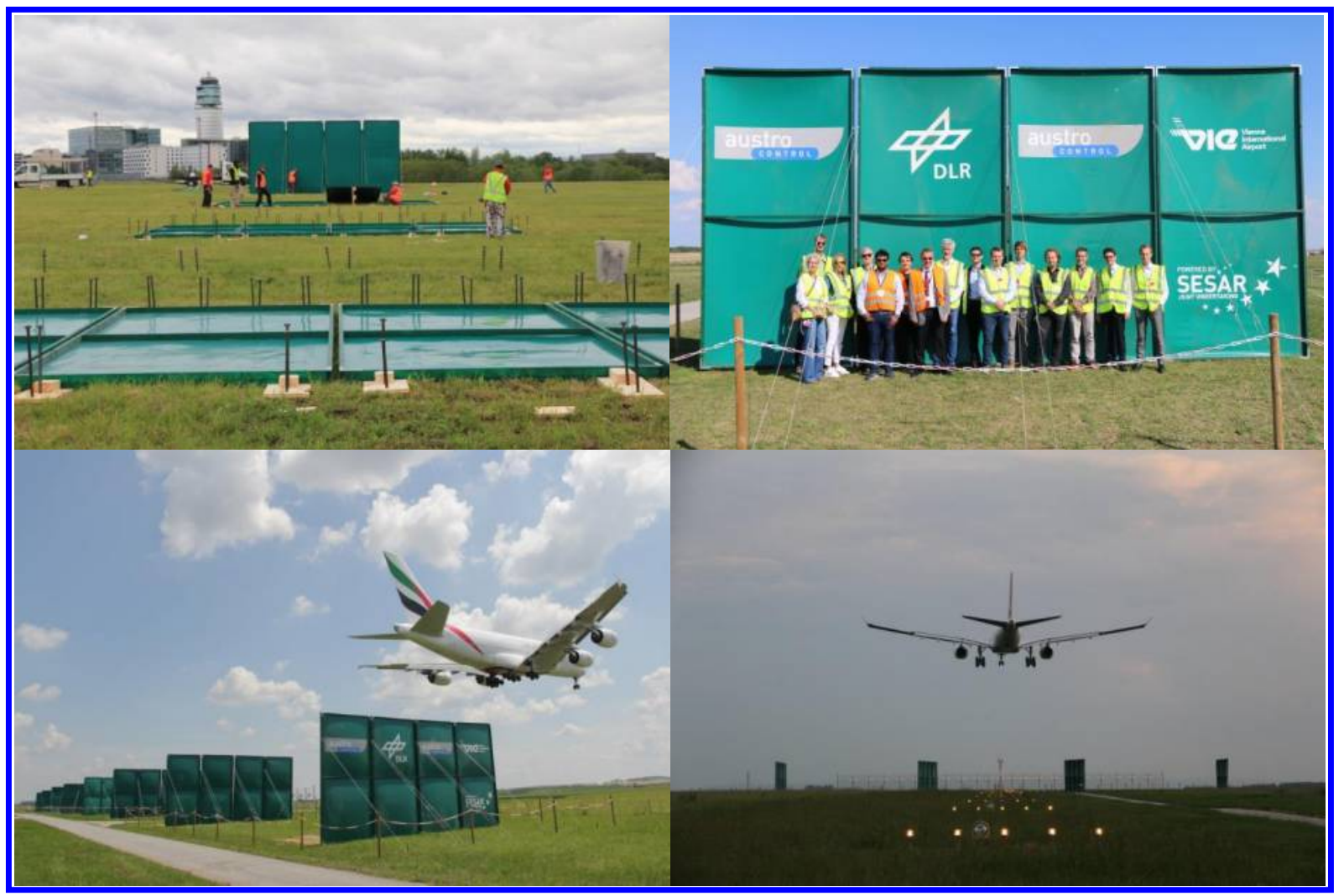

Figure 5 Impressions of the installation of plate line 2, the visitors' day, and overflights of plate line 1 (in clockwise order).

\section{Life Trial Results}

The measurement data used for the current analysis was collected within a time frame ranging from 6 May 2019 to 28 August 2019. On 13 days measurements with plate lines took place and 20 days saw measurements without plates. During that time frame 6888 approaches on runway 16 were conducted (source Mode-S data) from which 5039 were measured and 209 were processed. 1710 approaches with plates were measured from which 111 overflights were processed. Without plates 3163 approaches were captured by lidar from which 98 were processed.

\section{A. Evaluation Strategy}

An evaluation strategy has been developed focusing on safety aspects. For this purpose the data is filtered in various ways.

Quality Control: The lidar data is processed interactively employing an algorithm further developed in-house based on the method described in Ref. 19. During manual processing, the software doesn't indicate for a particular case whether the plates were folded up or down. The resulting vortex properties (lateral position, vertical position, and circulation against time) are subsequently quality controlled by visual inspection and erroneous data points are excluded. Such erroneous data points occur at a progressed state of vortex decay where the coherent structure of the vortices is getting lost and the vortices cannot be differentiated easily from atmospheric eddies.

Safety Corridor: Only wake vortices residing within a safety area of $\pm 50 \mathrm{~m}$ from the runway centerline are considered relevant, whereas vortices transported out of that safety area are neglected for the analysis. The dimensions of the safety area are inspired by Ref. 20 assuming a maximum lateral deviation of the aircraft from the extended centerline of $\pm 15 \mathrm{~m}$ plus a critical gap of $\pm 30 \mathrm{~m}$ between the vortex core and the aircraft fuselage. The resulting safety corridor of $\pm 45 \mathrm{~m}$ is rounded up to $\pm 50 \mathrm{~m}$.

Headwind Effects: For stronger headwinds so-called end effects are transported faster towards the lidar measurement planes accelerating vortex decay. As a consequence various headwind ranges have been considered in 
the data analysis (plots not shown). The main analysis focuses on headwinds lower than $2 \mathrm{~m} / \mathrm{s}$. This includes also cases with tailwinds where an accumulation of encounters was observed at Vienna airport ${ }^{6}$. The wind data consists of 2 min averages taken from the anemometer of runway 16 (WMA16) situated about $760 \mathrm{~m}$ from plate line 1.

Aircraft Type Effects: To enable the comparison of wake vortices generated by different aircraft types, the data characterizing vortex decay is partly normalized (made dimensionless). Normalized quantities are denoted by an asterisk (*). The vortex circulation (strength) data is normalized by its initial value $\Gamma_{0}=0.85 \mathrm{MLW} g / \rho \mathrm{b}_{0}$ TAS. The required values of true airspeed (TAS) in the lidar measurement planes are taken from the Mode-S protocol. Air density $\rho$ is retrieved from pressure and temperature also from the Mode-S protocol. The landing weight is assumed to correspond to $85 \%$ of the maximum landing weight (MLW). The initial vortex separation is computed according to $\mathrm{b}_{0}=\pi / 4 \mathrm{~B}$ assuming elliptical circulation distribution. Here $\mathrm{B}$ is the wing span. The characteristic vortex time scale $t_{0}$ is used to normalize vortex age. $t_{0}$ corresponds to the time the wake vortices initially need to descend one vortex separation $b_{0}$ and is calculated according to $t_{0}=2 \pi b_{0}^{2} / \Gamma_{0}$.

Decay Percentiles: In order to quantify the degree of circulation decay with and without the plate lines $0^{\text {th }}$ (minimum), $5^{\text {th }}, 25^{\text {th }}, 50^{\text {th }}$ (median), $75^{\text {th }}, 95^{\text {th }}$, and $100^{\text {th }}$ (maximum) percentiles are employed. On the one hand, vortex-age-binned percentiles are computed with dimensional bin widths of $20 \mathrm{~s}$. For example, this provides circulation values for the seven selected percentiles in a vortex age frame of $50 \mathrm{~s} \pm 10 \mathrm{~s}$ (see Figure 7). The normalized bin widths are adjusted to one vortex time scale $t_{0}\left( \pm 0.5 t_{0}\right)$ On the other hand, circulation-binned percentiles are used to extract different vortex lifetimes for given circulation strengths (see Figure 8). The circulation bin widths are adjusted to $100 \mathrm{~m}^{2} / \mathrm{s}\left( \pm 50 \mathrm{~m}^{2} / \mathrm{s}\right)$ for dimensional circulation values and to $0.1 \Gamma_{0}\left( \pm 0.05 \Gamma_{0}\right)$ for normalized circulation values.

\section{B. Analysis of Wake Vortex Behavior}

Figure 6 depicts the wake vortex behavior of all evaluated 209 landings comprising aircraft of the weight categories Super, Heavy, and Medium. Measurements with plate lines (PL) are denoted by dots in cold colors: green dots for the port vortex and blue dots for the starboard vortex. Warm colors are used for the reference cases without plates: red dots for the port vortex and magenta dots for the starboard vortex. The individual panels show vortex height $\mathrm{z}$ against vortex age $\mathrm{t}$ (top left), vortex height $\mathrm{z}$ over vortex lateral position $\mathrm{y}$ (top right, $\mathrm{y}=0$ corresponds to the extended runway centerline), vortex lateral position y against vortex age $t$ (center-left), vortex circulation $\Gamma$ over vortex age $t$ (center-right), lateral wind speed $v$ (positive away from lidar) over longitudinal wind speed $u$ (positive in flight direction) measured by anemometer WMA16 and derived from Mode-S data in the five lidar measurement planes (bottom left), normalized vortex circulation $\Gamma^{*}$ over normalized vortex age $t^{*}$ (bottom right). 

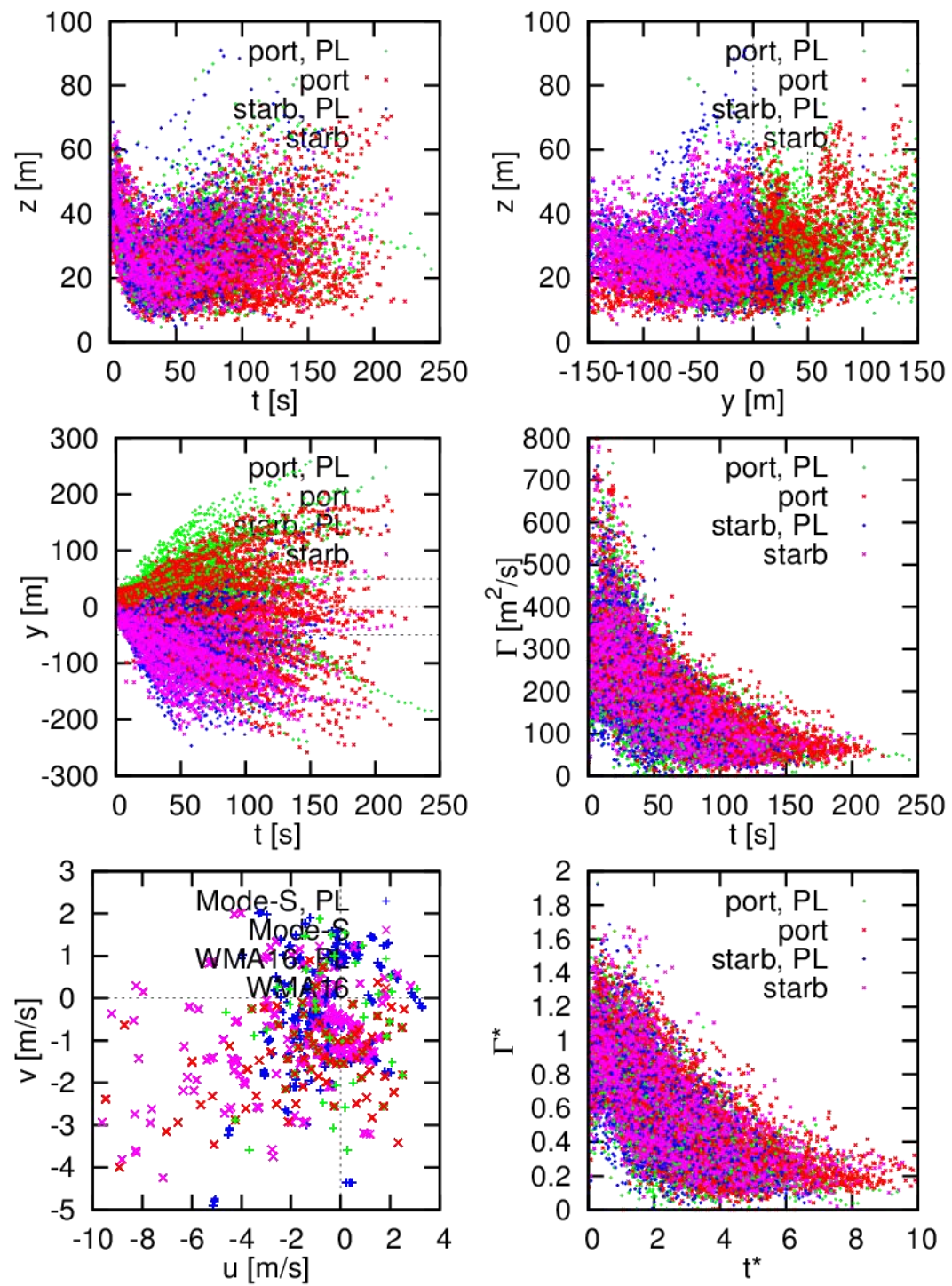

Figure 6 Wake vortex measurements of 209 landings (weight classes J, H, M) with prevailing wind conditions.
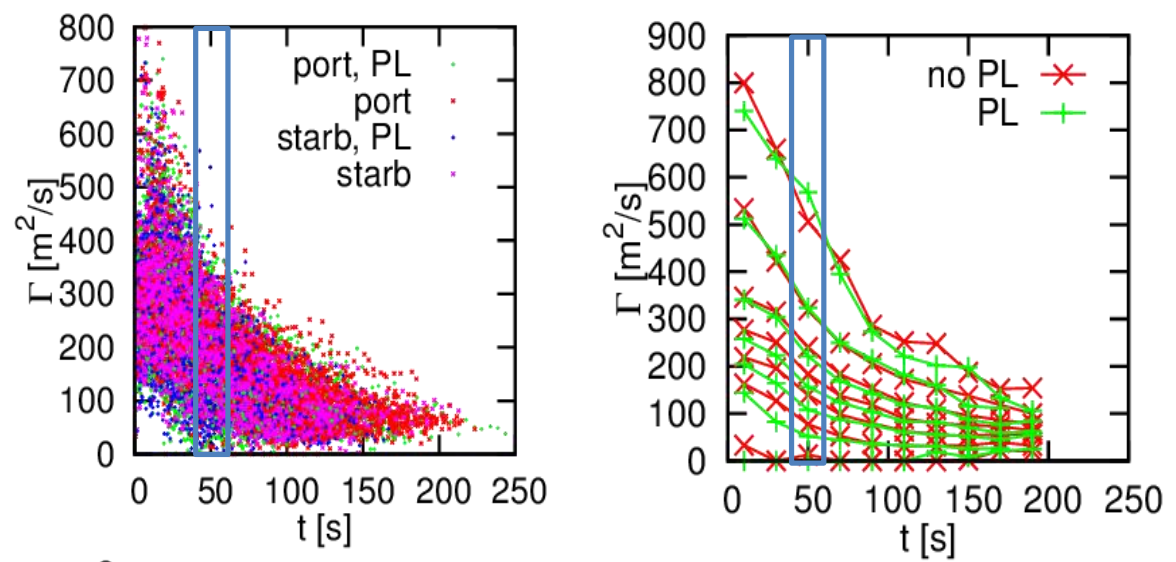

Figure 7 Scatter plot of circulation decay (left) and time-binned $0^{\text {th }}, 5^{\text {th }}, 25^{\text {th }}, 50^{\text {th }}, 75^{\text {th }}, 95^{\text {th }}$, and $100^{\text {th }}$ circulation percentiles (right). 

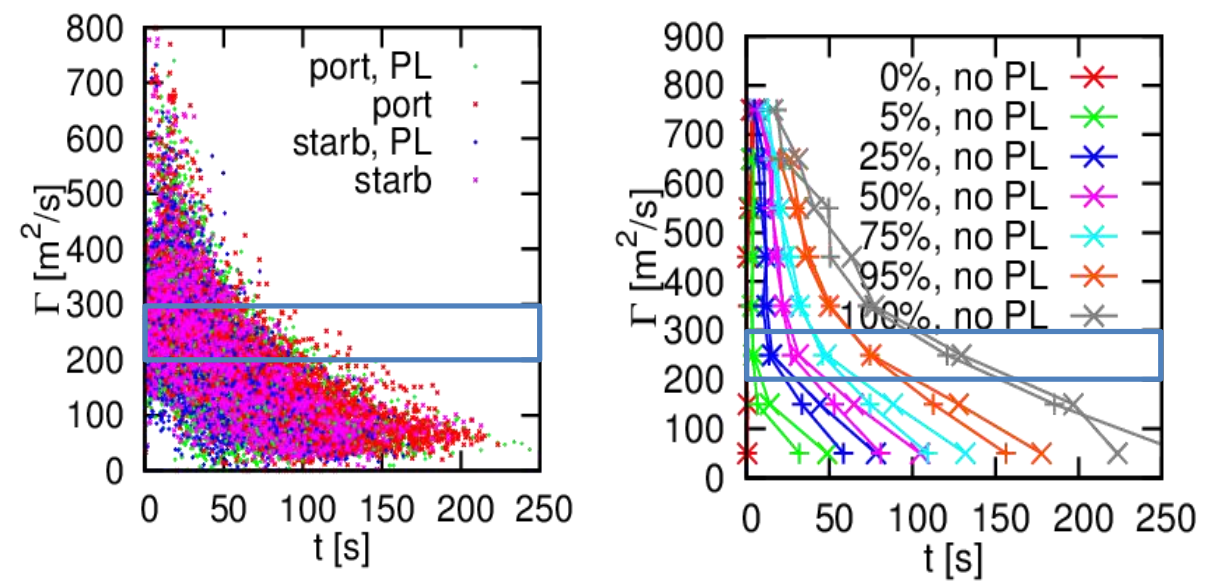

Figure 8 Scatter plot of circulation decay (left) and circulation-binned $0^{\text {th }}, 5^{\text {th }}, 25^{\text {th }}, 50^{\text {th }}, 75^{\text {th }}, 95^{\text {th }}$, and $100^{\text {th }}$ vortex age percentiles (right).

The scatter plots don't allow seeing the plate line effects clearly. For quantification of the plate line effects we employ the time-binned circulation percentiles (cf. Figure 7) and the circulation-binned vortex age percentiles (cf. Figure 8) as described under the keyword "decay percentiles" in section VA.

Figure 9 shows the vortex-age-binned and circulation-binned percentiles characterizing vortex decay of the 209 landings displayed in Figure 6. The decay rates of the dimensional vortex-age-binned percentiles (top left) don't indicate much difference between the flights with and without plates. The normalized percentiles (bottom left), however, indicate faster decay and reduced vortex lifetimes with the plates. Obviously, the mix of 13 different aircraft types of the Heavy category plus the A380 and two Medium type aircraft obscure the effects of the plates.

The circulation-binned percentiles provide a clearer picture: Initially the curves with and without plates fall on top of each other. When the plate effect starts to accelerate vortex decay, the curves start to deviate. So the circulation-binned curves feature a $\lambda$-shape.
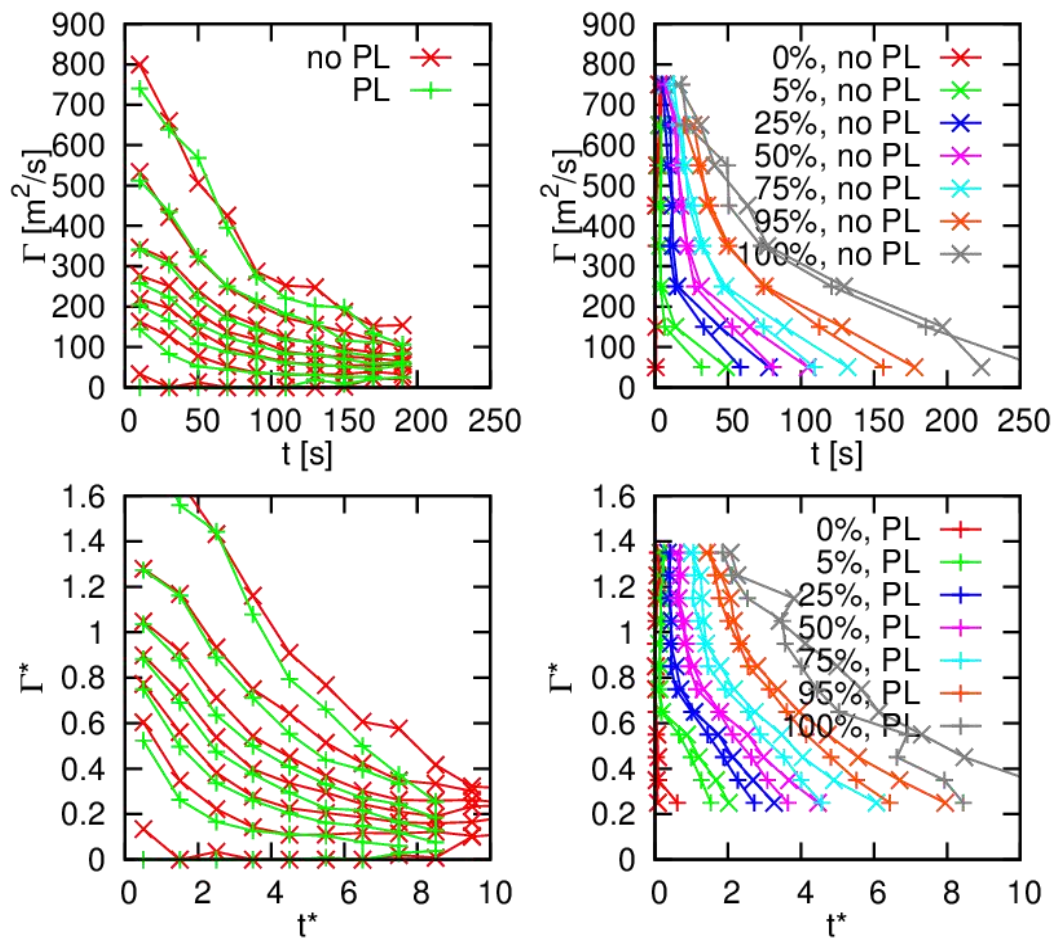

Figure 9 Vortex-age-binned (left) and circulation-binned percentiles characterizing vortex decay of 209 landings (weight classes J, H, M). Dimensional data above and normalized data below. 
The circulation-binned approach allows for a quantitative analysis of the vortex lifetime reduction. As an example, consider the dimensional circulation-binned vortex age values for the $95^{\text {th }}$ percentile, indicated in orange in the top-right chart in Figure 9. For vortices in the circulation range between 0 and $100 \mathrm{~m}^{2} / \mathrm{s}$, the vortex age at the $95^{\text {th }}$ percentile without plate lines is $175 \mathrm{~s}$ (indicated by " $\mathrm{x}$ "). This means that $95 \%$ of the vortices observed at this circulation range have a vortex age of $175 \mathrm{~s}$ or fewer. With erected plate lines (indicated by "+"), the vortex age at the $95^{\text {th }}$ percentile is reduced to $154 \mathrm{~s}$. This corresponds to a vortex lifetime reduction of $12.0 \%$. The lifetime reductions achieved at different circulation bins and different percentiles are given in Table 1. Because only the longer-living vortices are of interest, only values of the $50^{\text {th }}, 75^{\text {th }}$, and $95^{\text {th }}$ percentiles are considered. All values are positive which means that the plates reduce vortex lifetime. The lifetime reductions range between $1 \%$ and $23 \%$.

\begin{tabular}{rrrr}
\hline \multicolumn{1}{c}{$\begin{array}{c}\text { Dimensional } \\
\text { circulation range }\end{array}$} & \multicolumn{3}{c}{ Vortex lifetime reduction } \\
\cline { 2 - 4 } & $50^{\text {th }}$ percentile & $75^{\text {th }}$ percentile & $95^{\text {th }}$ percentile \\
\hline $0 \mathrm{~m}^{2} / \mathrm{s}-100 \mathrm{~m}^{2} / \mathrm{s}$ & $22.8 \%$ & $17.2 \%$ & $12.0 \%$ \\
$100 \mathrm{~m}^{2} / \mathrm{s}-200 \mathrm{~m}^{2} / \mathrm{s}$ & $18.2 \%$ & $15.9 \%$ & $12.0 \%$ \\
$200 \mathrm{~m}^{2} / \mathrm{s}-300 \mathrm{~m}^{2} / \mathrm{s}$ & $13.7 \%$ & $4.8 \%$ & $1.1 \%$ \\
\hline \hline $\begin{array}{c}\text { Normalized } \\
\text { circulation range }\end{array}$ & & Vortex lifetime reduction \\
\hline & $50^{\text {th }}$ percentile & $75^{\text {th }}$ percentile & $95^{\text {th }}$ percentile \\
\hline $0.3-0.4$ & $18.6 \%$ & $24.7 \%$ & $19.1 \%$ \\
$0.4-0.5$ & $16.1 \%$ & $18.5 \%$ & $17.6 \%$ \\
\hline
\end{tabular}

Table 1 Reduced wake vortex lifetimes of 209 landings (weight classes J, H, M) for different circulation ranges (dimensional above, normalized below) and different percentiles.

Following the arguments described under the keyword "headwind effects" in section VA., Figure 10 displays approaches with headwinds below $2 \mathrm{~m} / \mathrm{s}$ as measured by the WMA16. These include cases with tailwinds up to 3 $\mathrm{m} / \mathrm{s}$. Figure 10 left below shows that Mode-S wind measurements nevertheless reach up to headwinds of $6 \mathrm{~m} / \mathrm{s}$. This indicates substantial variability in the wind field but also uncertainties of measurement accuracies. Further, Figure 10 considers only vortices residing in the safety corridor extending $\mathrm{y}= \pm 50 \mathrm{~m}$.

The data sample consists of 85 approaches with erected plate lines corresponding to 239 vortex evolutions measured in lidar planes L1 to L4. Approaches over flat ground amount to 78 aircraft corresponding to 191 vortex evolutions. Combining the data of the different lidar planes L1 to L4 follows the rationale that wake vortex behavior shall be made safer anywhere where wake vortices might rebound to the flight path (data of lidar plane L5 were not yet available) and that the statistics become more significant the larger the data sample.

Figure 10 center-left indicates that many vortices are quickly transported out of the safety corridor but that also a substantial part of the vortices remain in the corridor until final decay. Both, the dimensional as well as the normalized circulation decay curves indicate longer life times and higher circulation values of the vortices developing over flat ground. 

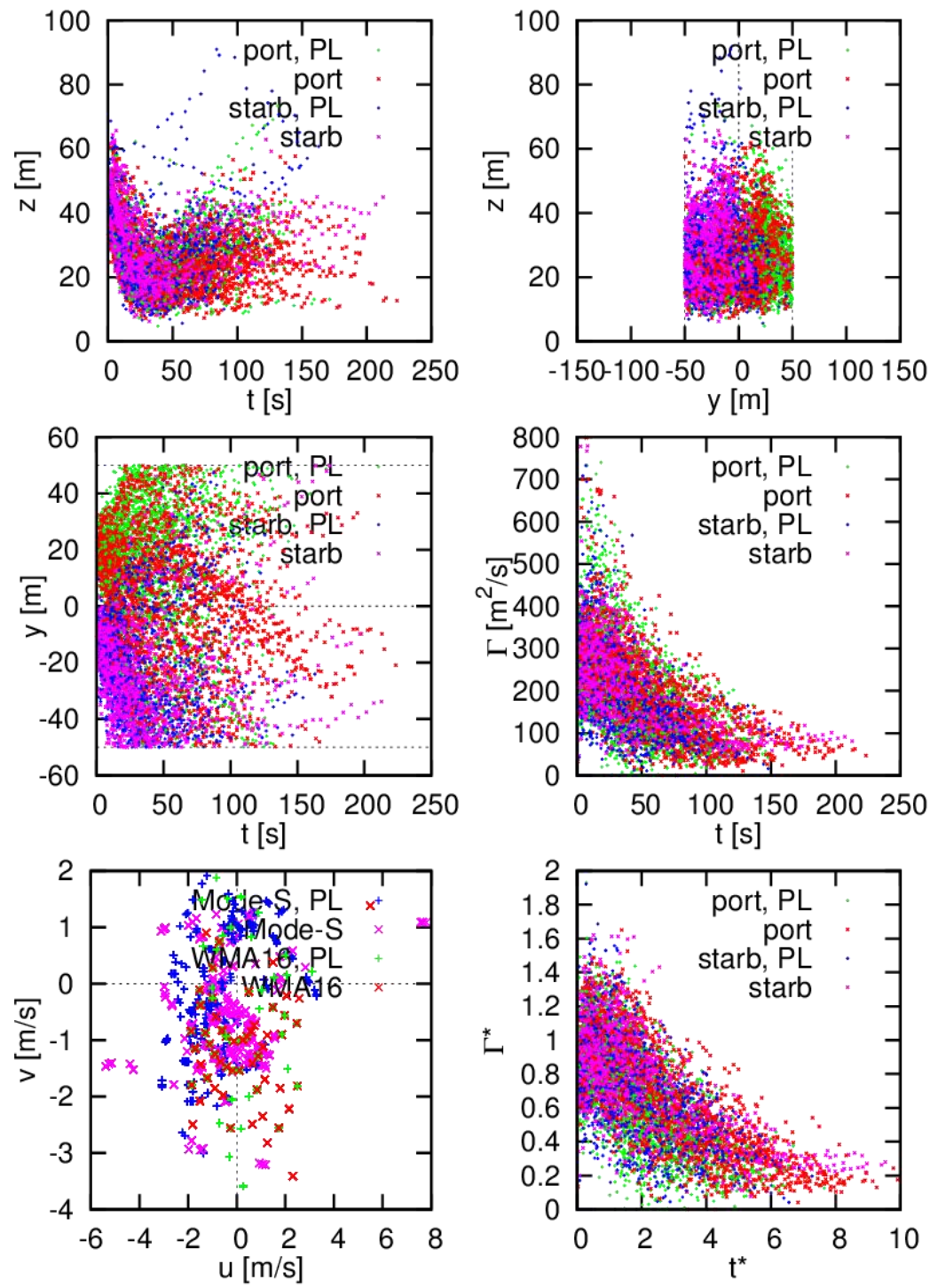

Figure 10 Wake vortex measurements of 163 landings (weight classes $\mathrm{J}, \mathrm{H}, \mathrm{M}$ ) in the $\pm 50 \mathrm{~m}$ safety corridor for headwinds lower than $2 \mathrm{~m} / \mathrm{s}$.

Applying the headwind filter and the $\pm 50 \mathrm{~m}$ safety corridor the percentile plots in Figure 11 reveal substantial lifetime reduction potential of the plate lines. The corresponding Table 2 features lifetime reductions of the longlived vortices (circulation bins $0-100 \mathrm{~m}^{2} / \mathrm{s}$ and $0.2-0.3$ ) between $26 \%$ and $39 \%$. The average of these lifetime reductions of the long-lived vortices amounts to $31.7 \%$.

Employing a larger safety corridor of $\pm 60 \mathrm{~m}$ width reduces this number slightly to $29.3 \%$, whereas a smaller safety corridor of $\pm 40 \mathrm{~m}$ width slightly increases the percentage to $32.4 \%$. These trends are expected, because previous numerical studies for the optimization of the plate line design indicated that additional plates ahead of a vortex strengthen the plate-induced vortex decay. 

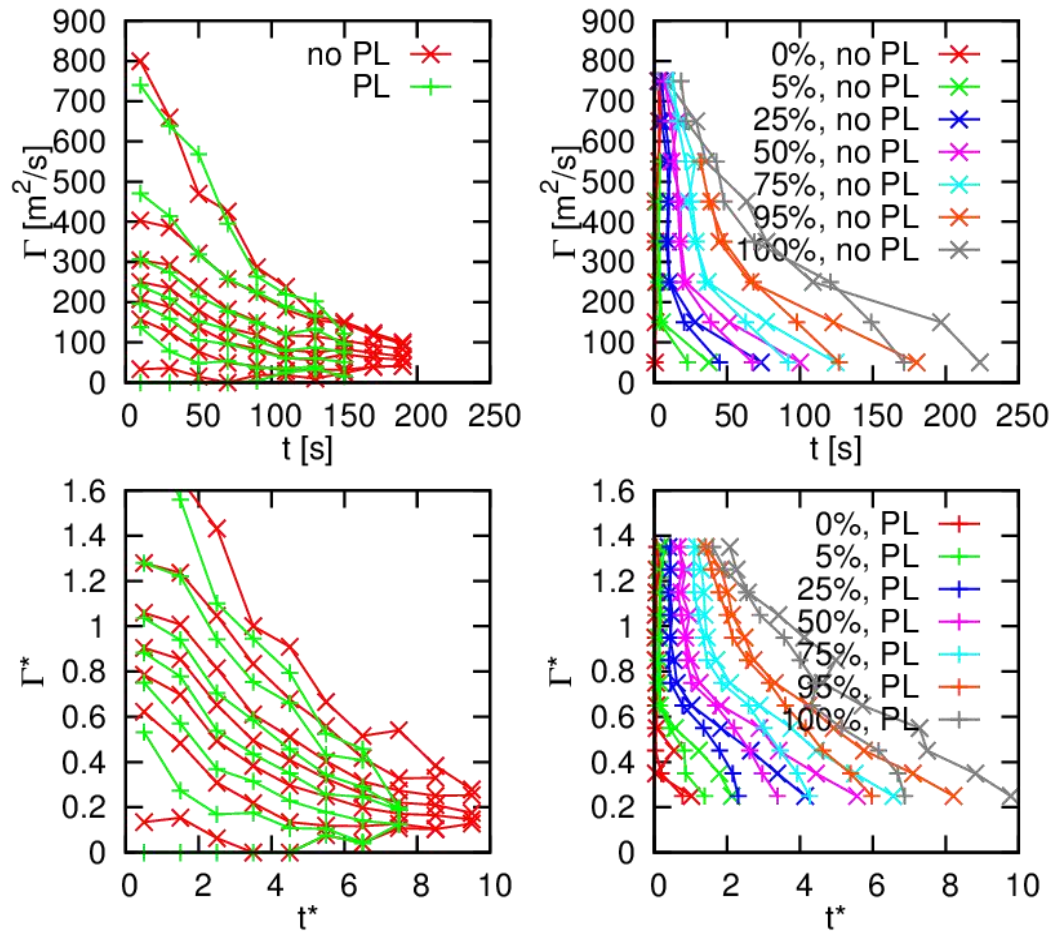

Figure 11 Vortex-age-binned (left) and circulation-binned percentiles characterizing vortex decay of 163 landings (weight classes J, H, M) in the $\pm 50 \mathrm{~m}$ safety corridor for headwinds lower than $2 \mathrm{~m} / \mathrm{s}$.

\begin{tabular}{rrrr}
\hline \multirow{2}{*}{$\begin{array}{c}\text { Dimensional } \\
\text { circulation range }\end{array}$} & \multicolumn{3}{c}{ Vortex lifetime reduction } \\
\cline { 2 - 4 } & $50^{\text {th }}$ percentile & $75^{\text {th }}$ percentile & $95^{\text {th }}$ percentile \\
\hline $0 \mathrm{~m}^{2} / \mathrm{s}-100 \mathrm{~m}^{2} / \mathrm{s}$ & $32.7 \%$ & $26.3 \%$ & $29.5 \%$ \\
$100 \mathrm{~m}^{2} / \mathrm{s}-200 \mathrm{~m}^{2} / \mathrm{s}$ & $24.5 \%$ & $18.4 \%$ & $20.4 \%$ \\
$200 \mathrm{~m}^{2} / \mathrm{s}-300 \mathrm{~m}^{2} / \mathrm{s}$ & $8.8 \%$ & $6.0 \%$ & $-2.9 \%$ \\
\hline \hline \multicolumn{1}{c}{$\begin{array}{r}\text { Normalized } \\
\text { circulation range }\end{array}$} & $50^{\text {th }}$ percentile & Vortex lifetime reduction & \\
\hline & $39.2 \%$ & $75^{\text {th }}$ percentile & $95^{\text {th }}$ percentile \\
\hline $0.2-0.3$ & $33.3 \%$ & $35.0 \%$ & $27.3 \%$ \\
$0.4-0.5$ & $23.4 \%$ & $28.6 \%$ & $24.1 \%$ \\
\hline
\end{tabular}

Table 2 Reduced wake vortex lifetimes of 163 landings (weight classes $\mathrm{J}, \mathrm{H}, \mathrm{M}$ ) in the $\pm 50 \mathrm{~m}$ safety corridor for headwinds lower than $2 \mathrm{~m} / \mathrm{s}$.

The variability of vortex behavior can be substantially reduced by considering only wake vortices generated by a single aircraft type. Within the weight category Heavy the B767-300ER was the most frequent aircraft type. Figure 12 depicts wake vortex measurements of 17 approaches of B767-300ER aircraft with plate lines corresponding to 46 vortex evolutions and 14 B767-300ER approaches without plate lines corresponding to 37 vortex evolutions. As in Figure 10 the plot considers wake behavior in the $\pm 50 \mathrm{~m}$ safety corridor and headwinds lower than $2 \mathrm{~m} / \mathrm{s}$. 

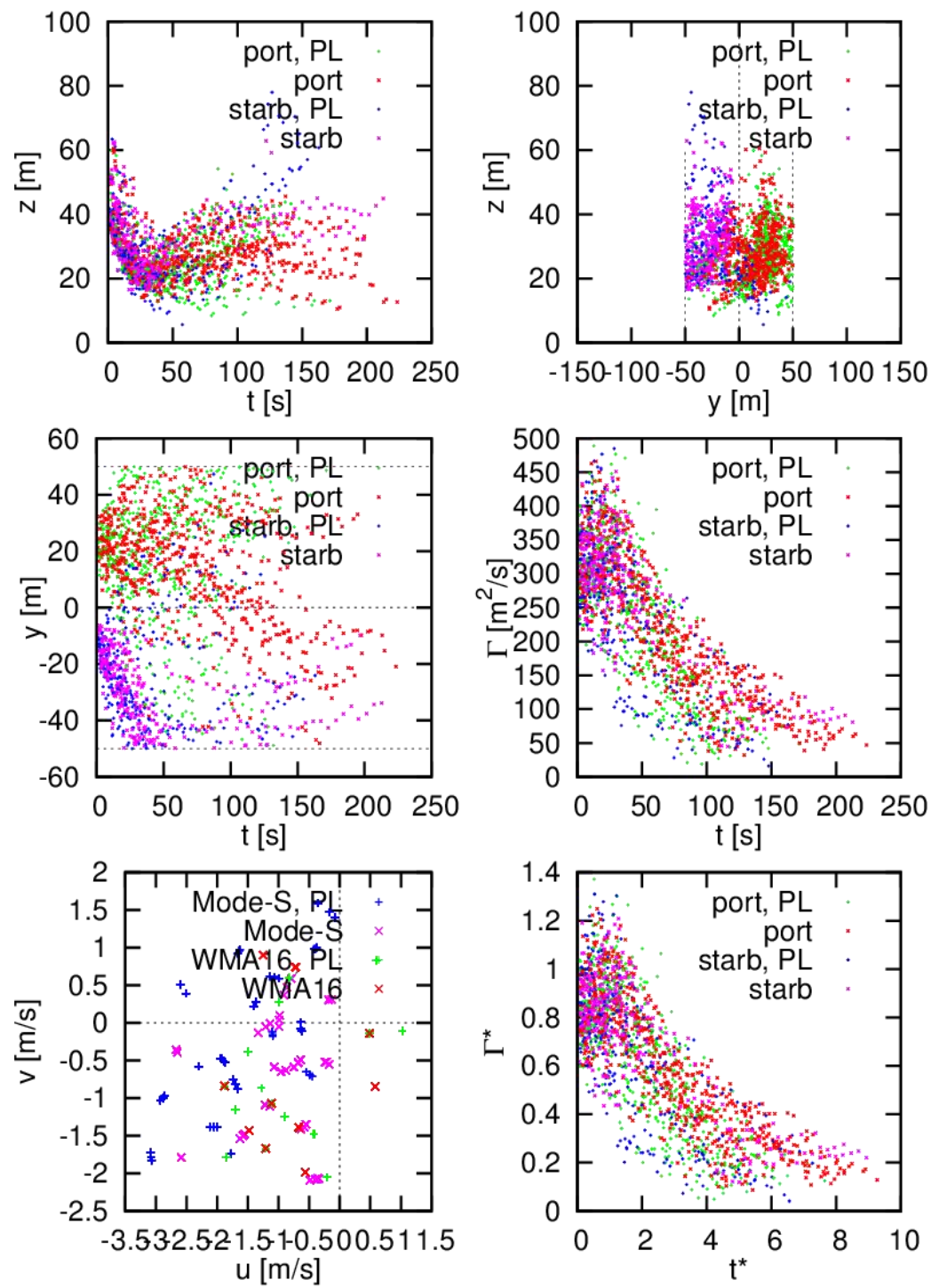

Figure 12 Wake vortex measurements of 31 landings of B767-300ER aircraft in the $\pm 50 \mathrm{~m}$ safety corridor for headwinds lower than $2 \mathrm{~m} / \mathrm{s}$.

The scatter plots indicate clearly that the circulation decays faster with erected plate lines. Considering the percentile plots in Figure 13 this becomes even more evident. During stages of progressed decay the vortex-agebinned circulation decay (left) progresses faster with the plates and the maximum lifetimes are noticeably reduced. The $\lambda$-shape of the circulation-binned percentiles is clearly visible. The individual percentile curves diverge into the $\lambda$ legs at a circulation level of $200-300 \mathrm{~m}^{2} / \mathrm{s}$ for the dimensional plot (top right) and at 0.6 to $0.7 \Gamma_{0}$ for the normalized representation (bottom right).

The reduced vortex lifetimes listed in Table 3 vary between $6 \%$ and $37 \%$ for the different criteria. The average of the lifetime reductions of the long-lived vortices (circulations bins $0-100 \mathrm{~m}^{2} / \mathrm{s}$ and $0.2-0.3$ ) amounts to $30.8 \%$. 

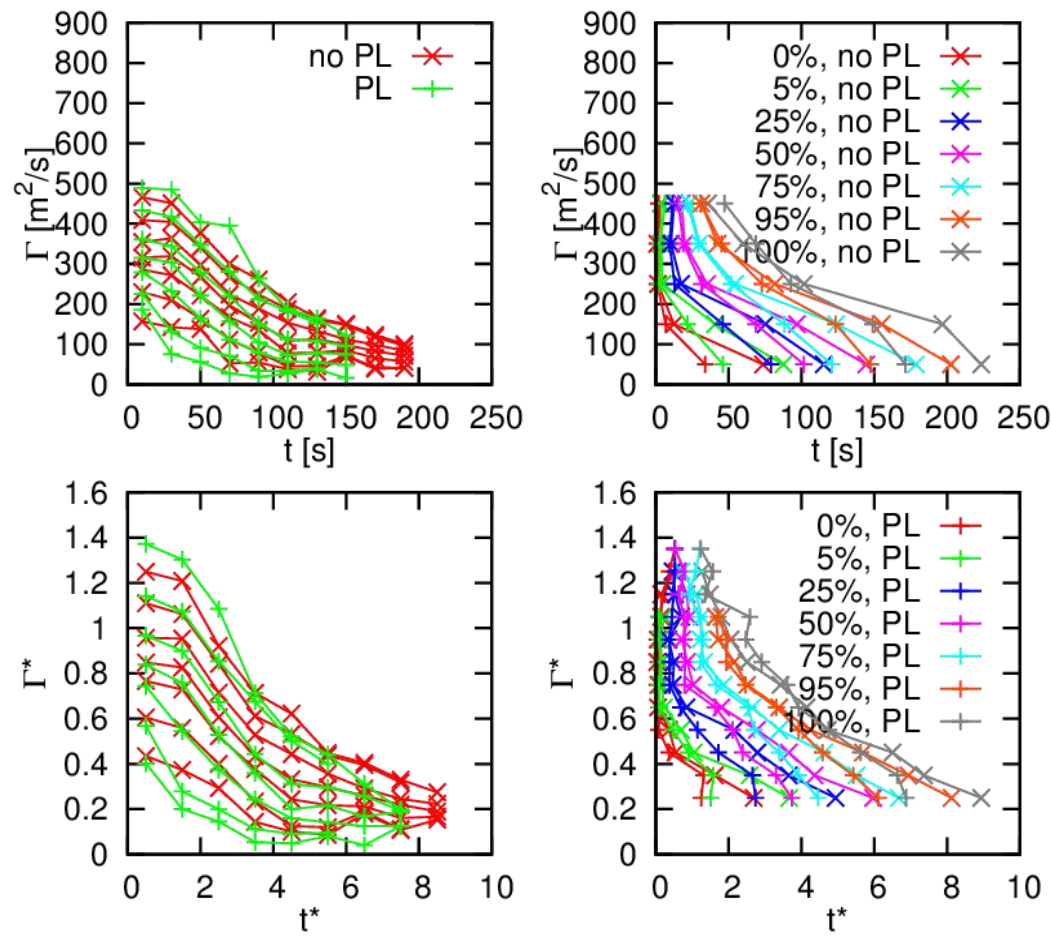

Figure 13 Vortex-age-binned (left) and circulation-binned percentiles (right) characterizing vortex decay of 31 landings of B763ER aircraft in the $\pm 50 \mathrm{~m}$ safety corridor for headwinds lower than $2 \mathrm{~m} / \mathrm{s}$.

\begin{tabular}{|c|c|c|c|}
\hline \multirow{2}{*}{$\begin{array}{c}\text { Dimensional } \\
\text { circulation range }\end{array}$} & \multicolumn{3}{|c|}{ Vortex lifetime reduction } \\
\hline & $50^{\text {th }}$ percentile & $75^{\text {th }}$ percentile & $95^{\text {th }}$ percentile \\
\hline $0 \mathrm{~m}^{2} / \mathrm{s}-100 \mathrm{~m}^{2} / \mathrm{s}$ & $29.6 \%$ & $32.3 \%$ & $27.2 \%$ \\
\hline $100 \mathrm{~m}^{2} / \mathrm{s}-200 \mathrm{~m}^{2} / \mathrm{s}$ & $29.1 \%$ & $28.7 \%$ & $20.5 \%$ \\
\hline $200 \mathrm{~m}^{2} / \mathrm{s}-300 \mathrm{~m}^{2} / \mathrm{s}$ & $11.1 \%$ & $5.7 \%$ & $10.9 \%$ \\
\hline \multirow{2}{*}{$\begin{array}{c}\text { Normalized } \\
\text { circulation range }\end{array}$} & \multicolumn{3}{|c|}{ Vortex lifetime reduction } \\
\hline & $50^{\text {th }}$ percentile & $75^{\text {th }}$ percentile & $95^{\text {th }}$ percentile \\
\hline $0.2-0.3$ & $37.4 \%$ & $33.2 \%$ & $24.8 \%$ \\
\hline $0.3-0.4$ & $24.3 \%$ & $28.8 \%$ & $21.8 \%$ \\
\hline $0.4-0.5$ & $34.6 \%$ & $26.7 \%$ & $19.6 \%$ \\
\hline
\end{tabular}

Table 3 Reduced wake vortex lifetimes of 31 landings of B763ER aircraft in the $\pm 50 \mathrm{~m}$ safety corridor for headwinds lower than $2 \mathrm{~m} / \mathrm{s}$.

With almost $28 \%$ of all landings the A320 constitutes by far the most frequent aircraft type at Vienna airport. As the A320neo (designated A20N) features the same maximum landing weight and wing span as the A320, it is added to the analysis of the A320 aircraft. As representative of the Medium weight category Figure 14 depicts the wake vortex behavior of 113 landings of A320 and A20N aircraft in the $\pm 50 \mathrm{~m}$ safety corridor for headwinds lower than 2 $\mathrm{m} / \mathrm{s}$. In detail the data sample contains 57 approaches with plate lines corresponding to 162 vortex evolutions and 56 approaches without plates represented by 132 vortex evolutions. Remarkably, the longest-lived A320 vortices reach a maximum lifetime of almost $200 \mathrm{~s}$. 
For this smaller aircraft type the maximum lifetimes are also noticeably reduced with the plates (see Figure 15) and the $\lambda$-shape of the circulation-binned percentiles is very clear. Lifetime reductions in Table 4 vary between $9 \%$ and $37 \%$. The average of the lifetime reductions of the long-lived vortices (circulation bins $0-100 \mathrm{~m}^{2} / \mathrm{s}$ and $0.2-$ 0.3 ) amounts to $31.4 \%$.
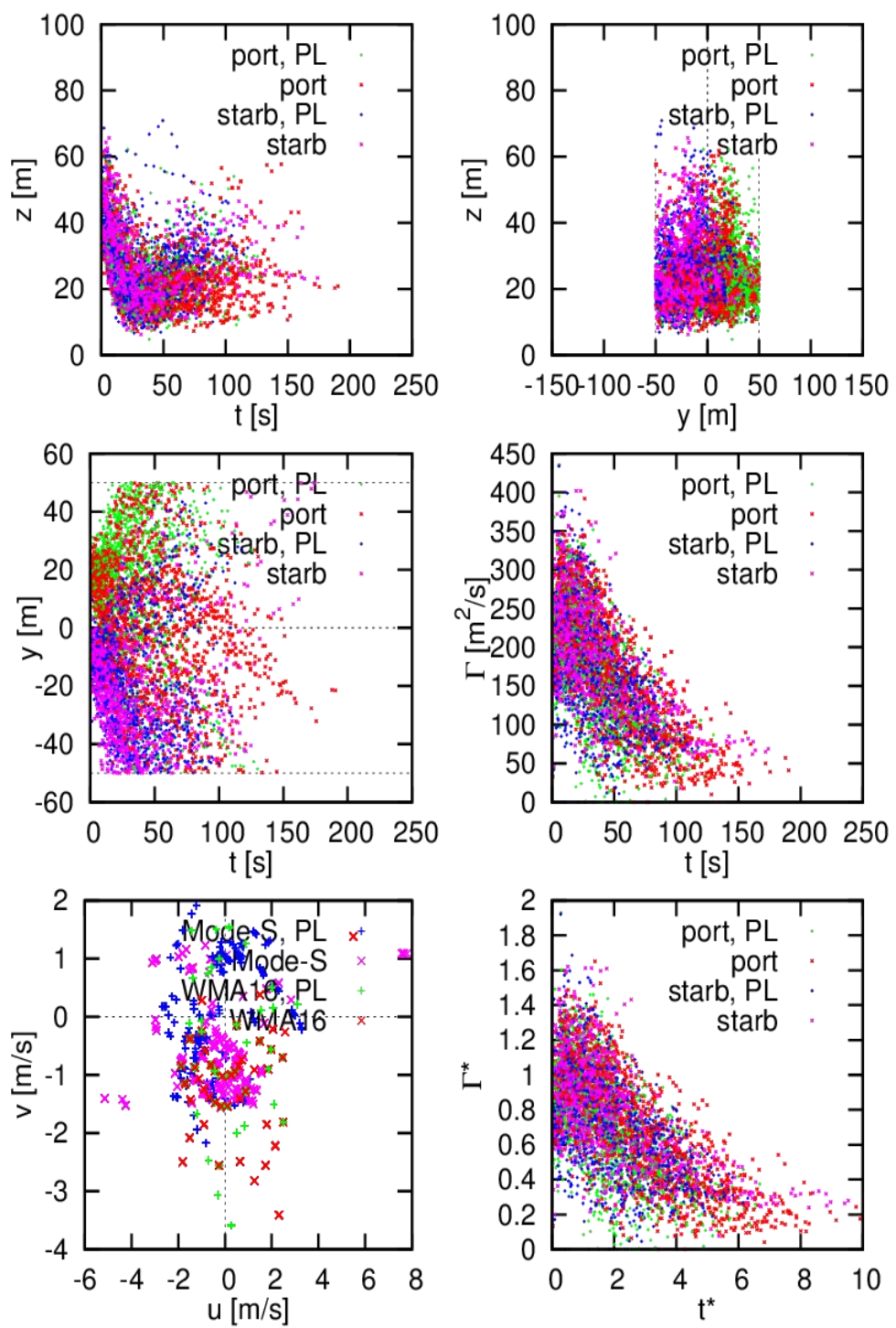

Figure 14 Wake vortex behavior of 113 landings of A320 and A20N aircraft in the $\pm 50 \mathrm{~m}$ safety corridor for headwinds lower than $2 \mathrm{~m} / \mathrm{s}$. 

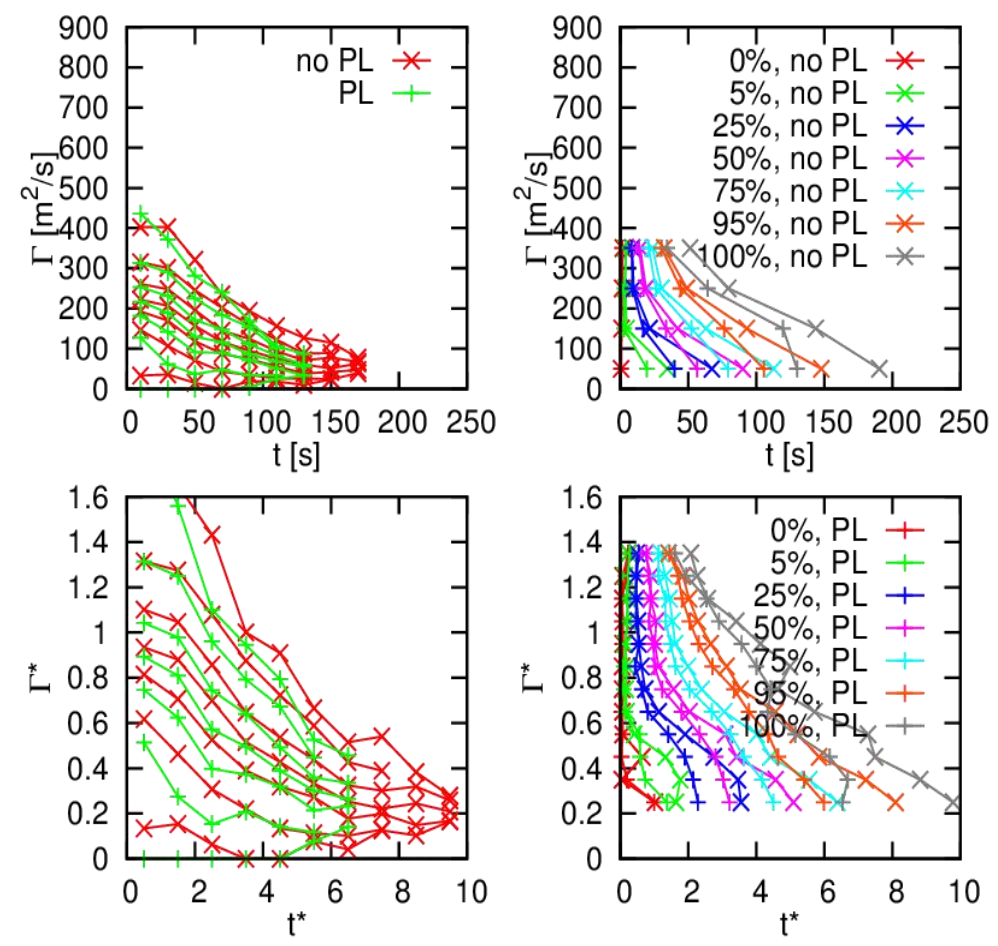

Figure 15 Vortex-age-binned (left) and circulation-binned (right) percentiles characterizing vortex decay of 113 landings of A320 and A20N aircraft in the $\pm 50 \mathrm{~m}$ safety corridor for headwinds lower than $2 \mathrm{~m} / \mathrm{s}$.

\begin{tabular}{|c|c|c|c|}
\hline \multirow{2}{*}{$\begin{array}{c}\text { Dimensional } \\
\text { circulation range }\end{array}$} & \multicolumn{3}{|c|}{ Vortex lifetime reduction } \\
\hline & $50^{\text {th }}$ percentile & $75^{\text {th }}$ percentile & $95^{\text {th }}$ percentile \\
\hline $0 \mathrm{~m}^{2} / \mathrm{s}-100 \mathrm{~m}^{2} / \mathrm{s}$ & $37.4 \%$ & $29.6 \%$ & $28.6 \%$ \\
\hline $100 \mathrm{~m}^{2} / \mathrm{s}-200 \mathrm{~m}^{2} / \mathrm{s}$ & $20.2 \%$ & $16.9 \%$ & $17.9 \%$ \\
\hline $200 \mathrm{~m}^{2} / \mathrm{s}-300 \mathrm{~m}^{2} / \mathrm{s}$ & $8.5 \%$ & $13.2 \%$ & $9.6 \%$ \\
\hline \multirow{2}{*}{$\begin{array}{c}\text { Normalized } \\
\text { circulation range }\end{array}$} & \multicolumn{3}{|c|}{ Vortex lifetime reduction } \\
\hline & $50^{\text {th }}$ percentile & $75^{\text {th }}$ percentile & $95^{\text {th }}$ percentile \\
\hline $0.2-0.3$ & $36.9 \%$ & $29.5 \%$ & $26.1 \%$ \\
\hline $0.3-0.4$ & $33.8 \%$ & $25.0 \%$ & $25.1 \%$ \\
\hline $0.4-0.5$ & $18.1 \%$ & $17.8 \%$ & $20.6 \%$ \\
\hline
\end{tabular}

Table 4 Reduced wake vortex lifetimes of 113 landings of A320 and A20N aircraft in the $\pm 50 \mathrm{~m}$ safety corridor for headwinds lower than $2 \mathrm{~m} / \mathrm{s}$.

\section{Conclusion}

In this study wake vortex behavior of 5039 approaches has been measured in four different lidar measurement planes. From these 209 approaches have been processed and used for the current analysis. The exclusion of landings with headwinds above $2 \mathrm{~m} / \mathrm{s}$ leaves 85 approaches with plate lines (corresponding to 239 vortex evolution measurements in the individual lidar planes) which have been compared to 78 approaches (191 vortex evolutions) over flat ground. The data collection has been continued until November 2019 and the data processing is ongoing. More detailed analyses will be accomplished and documented in another AIAA paper.

The developed evaluation strategy focuses on safety aspects: 
- The conducted analysis employs an aircraft safety corridor extending $\pm 50 \mathrm{~m}$ from the runway centreline. Vortices transported out of that safety area are neglected for the analysis. The sensitivity to the width of the safety corridor turned out to be weak. A smaller safety corridor slightly increases the plate line efficiency, because additional plates ahead of a vortex strengthen the plate-induced vortex decay.

- Cases with headwinds stronger than $2 \mathrm{~m} / \mathrm{s}$ have been excluded, because strong headwinds support the transport of end effects (occurring during touchdown and accelerating vortex decay) into the measurement planes. Encounter frequencies and go-around rates are highest at weak headwinds or even tailwinds.

- The analysis combines data of all the available lidar measurement planes, because the accelerated vortex decay should be effective all along the stretch where rebounding vortices may reach up to the flight corridor.

- Further the analysis focuses on long-lived wake vortices. Therefore, the accelerated circulation decay is evaluated in dimensional circulation bins ranging from 0 to $100 \mathrm{~m}^{2} / \mathrm{s}$ and normalized circulation bins ranging from $20 \%$ to $30 \%$ of the initial circulation (lower values cannot be evaluated reasonably well, because the vortices lose their coherent structure and cannot be differentiated uniquely from environmental turbulence). Within these circulation bins we consider the median, the $75^{\text {th }}$ percentile, and the $95^{\text {th }}$ percentile of the vortex lifetime. In order to further condense the accelerated circulation decay into a single number, the six values resulting from the two circulation bins and the three percentiles are averaged.

Following all the above listed criteria, the lifetime of the long-lived vortices in the safety corridor is reduced by $32 \%$ for all (163) landings comprising medium, heavy, and super weight class aircraft. For this 239 vortex evolution measurements with plates and 191 vortex evolutions without plates have been considered.

As a representative for heavy aircraft landings of 29 B763 aircraft (46 vortex evolutions with plates and 37 vortex evolutions without plates) have been assessed separately leading to a $31 \%$ vortex lifetime reduction. For 113 medium weight category A320 and A20N aircraft (162 vortex evolutions with plates and 132 vortex evolutions without plates) the vortex lifetime could be reduced by $31 \%$.

In summary it can be concluded that the plate lines reduce the lifetime of long-lived vortices in a safety corridor along the final approach on average by more than $30 \%$.

More detailed analysis of the measurement data, shedding more light on the effects of individual aircraft types, flight altitudes, and environmental conditions, will be conducted in SESAR 2020 Wave2 VLD3 and documented in another AIAA paper to be presented at the AVIATION Forum 2020 in Reno ${ }^{21}$.

\section{Acknowledgments}

This project has received funding within the framework of the SESAR Joint Undertaking "Increased Runway and Airport Throughput" project (PJ.02 EARTH) within the European Union's Horizon 2020 research and innovation programme under grant agreement No 731781 and the German Aerospace Research Center (DLR) project "Wetteroptimierter Luftverkehr". The priceless contributions from numerous colleagues of Austro Control $\mathrm{GmbH}$, MeteoServe Wetterdienst GmbH, Vienna International Airport, Leonardo Germany GmbH, and RPG Radiometer Physics GmbH, who will co-author the AVIATION Forum 2020 paper, only made this endeavor possible and are highly appreciated.

\section{References}

'1 Hallock, J.N., Holzäpfel, F., “A Review of Recent Wake Vortex Research for Increasing Airport Capacity”, Progress in Aerospace Sciences, Vol. 98, 2018, pp. 27-36, https://doi.org/10.1016/j.paerosci.2018.03.003.

${ }^{2}$ Eurocontrol, "European Aviation in 2040 - Challenges of growth 2018", 2 Oct. 2018, https://www.eurocontrol.int/publication/challengesgrowth-2018.

${ }^{3}$ Critchley, J., Foot, P., "UK CAA Wake Vortex Database: Analysis of Incidents Reported Between 1982 and 1990”, Civil Aviation Authority, CAA Paper 91, 1991.

${ }^{4}$ WakeNet3-Europe, “Aircraft Wake Vortex State-of-the-Art \& Research Needs", compiled by F. Holzäpfel et al., issued by A. Reinke, C. Schwarz, 2015, 201 pages, doi.org/10.17874/BFAEB7154B0.

$\checkmark 5$ Holzäpfel, F., Steen, M., "Aircraft Wake-Vortex Evolution in Ground Proximity: Analysis and Parameterization,” AIAA Journal, Vol. 45, 2007, pp. 218-227.

${ }^{6}$ Holzäpfel, F., "Analysis of potential wake vortex encounters at a major European airport," Aircraft Engineering and Aerospace Technology, Vol. 89, 2017, pp. 634-643, http://dx.doi.org/10.1108/AEAT-01-2017-0043.

${ }^{7}$ Crouch, J.D., Czech, M.J., "Comparative wake wake-turbulence assessments and findings for the B747-8", 4th WakeNet3-Europe workshop, Langen, Germany, 2012, http://www.wakent.eu/index.php?id=185. 
${ }^{8}$ Duffy, K., Deluca, A., “One year of time-based separation at London's Heathrow airport”, WakeNet-USA, Port Authority of NY \& NJ, New York City, 2016.

${ }^{9}$ SAFO 14007, "Safety Alert for Operators, Federal Aviation Administration," 2014, http://www.faa.gov/other_visit/aviation_industry/airline operators/airline_safety/safo.

${ }^{10}$ EUROCONTROL, 2016, http://www.eurocontrol.int/news/recat-eu-now-use-paris-charles-de-gaulle.

${ }^{11}$ Holzäpfel, F., Stephan, A., Heel, T., Körner, S., "Enhanced Wake Vortex Decay in Ground Proximity Triggered by Plate Lines," Aircraft Engineering and Aerospace Technology, Vol. 88, 2015, doi: 10.1108/AEAT-02-2015-0045.

${ }^{12}$ Stephan, A., Holzäpfel, F., Misaka, T., "Aircraft Wake-Vortex Decay in Ground Proximity - Physical Mechanisms and Artificial Enhancement," Journal of Aircraft, Vol. 50, 2013, DOI:10.2514/1.C032179, pp. 1250 - 1260.

${ }^{13}$ Stephan, A., Holzäpfel, F., Misaka, T., Geisler, R., Konrath, R., "Enhancement of aircraft wake vortex decay in ground proximity," CEAS Aeronautical Journal, Vol. 5, 2014, pp. 109-125, DOI 10.1007/s13272-013-0094-8.

${ }^{14}$ Stephan, A., Schrall, J., Holzäpfel, F., "Numerical Optimization of Plate-Line Design for Enhanced Wake-Vortex Decay," Journal of Aircraft, Vol. 54, 2017, pp. 995-1010, http://dx.doi.org/10.2514/1.C033973.

${ }^{15}$ Wang, C.H.J., Zhao, D., Schlüter, J., Holzäpfel, F., Stephan, A., "LES study on the shape effect of ground obstacles on wake vortex dissipation", Aerospace Science and Technology, Vol. 63, 2017, pp. 245-258, http://dx.doi.org/10.1016/j.ast.2016.12.032.

$\checkmark{ }^{16}$ Wang, C.H.J., Zhao, D., Schlüter, J., Stephan, A., Holzäpfel, F., "Computational Investigation of Varying Plate-Line Geometry and Placement on Wake Vortex Dissipation”, Journal of Aircraft, Vol. 55, 2018, pp. 133-144, https://doi.org/10.2514/1.C034346.

${ }^{17}$ Geise, R., Neubauer, B., Zimmer, G., "Scaled Measurements of Multipath Propagation and Navigations Systems - a Practical Example for ILS," 2019 Joint International Symposium on Electromagnetic Compatibility, Sapporo and Asia-Pacific International Symposium on Electromagnetic Compatibility (EMC Sapporo/APEMC), 2019, http://dx.doi.org/10.23919/EMCTokyo.2019.8893769.

${ }^{18}$ Stephan, A., Holzäpfel, F., Misaka, T., "Hybrid simulation of wake-vortex evolution during landing on flat terrain and with plate line", International Journal of Heat and Fluid Flow, Vol. 49, 2014, pp. 18-27, http://dx.doi.org/10.1016/j.ijheatfluidflow.2014.05.004.

${ }^{19}$ Smalikho, I.N., Banakh, V.A., Holzäpfel, F., Rahm, S., "Method of radial velocities for the estimation of aircraft wake vortex parameters from data measured by coherent Doppler lidar," Optics Express, Vol. 23, pp. A1194-A1207, 2015, http://dx.doi.org/10.1364/OE.23.0A1194.

${ }^{20}$ Gurke, T., Lafferton, H., "The Development of the Wake Vortices Warning System for Frankfurt Airport: Theory and Implementation," Air Traffic Control Quarterly, Vol. 5, 1997.

${ }^{21}$ Holzäpfel, F., Borek, G., Czekala, H., Floh, A., Gerz, T., Kauczok, S., Kern, C., Kerschbaum, M., Körner, S., Maschwitz, G., Nossal, R., Oswald, L., Rotshteyn, G., Schiefer, C., Schwarzenbacher, J., Stephan, A., Stieber, M., Strauss, L., Strobel, M., Weiß, C., Wildmann, N., "Reduction of Wake Vortex Lifetime During Final Approach Via Plate Lines," AIAA Aviation Forum 2020, Reno. 